\title{
Analisis Data Panel pada Tingkat Pengangguran Terbuka Kabupaten/Kota di Pulau Jawa
}

\author{
${ }^{1}$ Hasih Pratiwi, ${ }^{2}$ Ardina Nilam Prawastyorini, ${ }^{3}$ Sugiyanto
}

\begin{abstract}
s
Unemployment rate is the percentage of the number of unemployed to the total labor force, it has become some problems in economic development. The aim of this study is to choose the best model between common, fixed, and random effects in modeling open unemployment rate of regency/city in Java. It based on open unemployment rate with several influence factors in Java Island 2010-2016 which are panel data types. The best model choosen based on the results of the Chow test and Hausman test. The fixed effect model was obtained as the best model with a value of adjusted $R^{2} 79,26$ percent.
\end{abstract}

Keywords: open unemployment rate, panel data, fixed effect model, chow test, hausman test

\begin{abstract}
Abstrak
Pengangguran merupakan salah satu permasalahan dalam bidang pembangunan ekonomi. Presentase jumlah pengangguran terhadap jumlah angkatan kerja digambarkan dengan Tingkat Pengangguran Terbuka (TPT). Penelitian ini bertujuan untuk memilih model terbaik antara common, fixed, dan random effect dalam memodelkan TPT kabupaten/kota di Pulau Jawa. Penelitian ini menggunakan data tingkat pengangguran terbuka beserta faktor-faktor yang berpengaruh di Pulau Jawa rentang waktu 2010 hingga 2016 yang bertipe data panel. Model terbaik dipilih berdasarkan hasil uji Chow dan uji Hausman. Berdasarkan kedua uji tersebut didapatkan model fixed effect sebagai model terbaik untuk memodelkan TPT kabupaten/kota di Pulau Jawa dengan nilai adjusted $R^{2}$ sebesar $79,26 \%$.
\end{abstract}

Kata kunci: tingkat pengangguran terbuka, data panel, model fixed effect, uji Chow, uji Hausman.

\section{Pendahuluan}

Salah satu permasalahan pembangunan di Indonesia yang masih menjadi suatu tantangan adalah kondisi kependudukan. Indonesia memiliki jumlah penduduk yang banyak, sedangkan dalam aspek kualitas dapat dikatakan masih rendah. Masalah pengangguran muncul dikarenakan ada ketimpangan antara jumlah lapangan pekerjaan yang tersedia dengan jumlah angkatan kerja. Pengangguran adalah suatu keadaan di mana seseorang yang tergolong dalam angkatan kerja ingin mendapatkan pekerjaan tetapi belum dapat memperolehnya [9]. Pulau Jawa memilki

\footnotetext{
${ }^{1,2,3}$ Program Studi Statistika, Universitas Sebelas Maret, Surakarta

Email address: ${ }^{1}$ hpratiwi@mipa.uns.ac.id,

${ }^{2}$ nilamprawastyorini@student.uns.ac.id, ${ }^{3}$ sugiyanto@staff.uns.ac.id
} 


\section{Hasih Pratiwi, Ardina Nilam Prawastyorini, Sugiyanto}

jumlah penduduk besar hal tersebut membuat Pulau Jawa tidak terlepas dari masalah pengangguran.

Pulau Jawa terdiri atas atas enam Provinsi yaitu DKI Jakarta, Jawa Barat, Jawa Tengah, DIY, Jawa Timur, dan Banten. Menurut Badan Pusat Statistik [1] tingkat pengangguran terbuka tertinggi se-Indonesia ditempati oleh Provinsi Banten yaitu sebesar 8,52\%. Posisi kedua ditempati oleh Provinsi Jawa Barat yaitu sebesar $8,17 \%$. Keadaan tersebut tentunya kurang baik bagi perekonomian di Pulau Jawa.

Perubahan TPT pada setiap kabupaten/kota pada seluruh Provinsi di Pulau Jawa mengindikasikan bahwa lokasi dan waktu berpengaruh terhadap TPT, metode,regresi data panel digunakan dalam penelitian ini karena dianggap paling baik dalam menduga dan mengukur akibat yang secara sederhana tidak dapat dilihat pada data cross section atau time series saja. Data panel merupakan gabungan dari data cross section dan data time series. Salah satu keunggulan data panel yaitu memiliki jumlah observasi yang besar. Jumlah observasi yang besar dapat meningkatkan derajat bebas, sehingga dapat mengurangi adanya kolinearitas diantara variabel independen. Variasi dan fluktuasi angka TPT dari tahun ke tahun untuk masing-masing daerah menggambarkan bahwa waktu dan lokasi berpengaruh terhadap TPT sehingga waktu (tahun) diperhitungkan dalam pemodelan. Tujuan dalam penelitian ini adalah mendapatkan model regresi data panel untuk TPT di Pulau Jawa periode 2010 hingga 2016.

\section{Tinjauan Pustaka \\ 2.1 Data Panel}

Terdapat tiga tipe data secara umum yaitu data cross section, data time series, dan data panel. Data panel merupakan gabungan dari data cross section dan data time series [8]. Salah satu keunggulan data panel menurut Gujarati [4] adalah memiliki jumlah observasi yang besar, sehingga dapat miningkatkan derajat bebas. Derajat bebas yang besar dapat mengurangi kolinearitas diantara variabel indepeden. Menurut Gujarati dan Porter [5], model regresi data panel secara umum adalah

$$
\begin{gathered}
Y_{i t}=\beta_{i t}+\beta_{1} X_{1 i t}+\beta_{2} X_{2 i t}+\cdots+\beta_{j} X_{j i t}+\varepsilon_{i t} \\
i=1,2, \ldots, N ; j=1,2, \ldots, K ; t=1,2, \ldots, T
\end{gathered}
$$

dimana

$Y_{i t}$ : variabel dependen observasi ke- $i$ periode waktu ke- $t$,

$\beta_{i t}$ : koefisien intersep observasi ke- $i$ periode waktu ke- $t$,

$\beta_{j}$ : koefisien slope,

$X_{j i t}$ : variabel independen ke-j observasi ke- $i$ untuk periode waktu ke- $t$,dan

$\varepsilon_{i t}$ : sisaan observasi ke- $i$ untuk periode waktu ke- $t$ yang berdistribusi normal dengan mean 0 dan variansi $\sigma^{2}$.

Terdapat tiga model estimasi pada regresi data panel yaitu model common, fixed, dan random effect.

a. Model Common Effect

Mengasumsikan tidak ada perbedaan nilai intersep dan slope pada hasil regresi. Model common effect menurut Nachrowi dan Usman [7] sebagai berikut 


$$
Y_{i t}=\alpha+\sum_{j=1}^{K} \beta_{j} X_{j i t}+\varepsilon_{i t} ; i=1,2, \ldots, N, j=1,2, \ldots, K, t=1,2, \ldots, T
$$

b. Model fixed effect

Mengasumsikan bahwa koefisien slope bernilai konstan tetapi nilai intersep tidak konstan. Berikut adalah model fixed effect [4]

$$
Y_{i t}=\alpha_{i}+\beta_{1} X_{1 i t}+\beta_{2} X_{2 i t}+\beta_{3} X_{3 i t}+\cdots+\beta_{j} X_{j i t}+\varepsilon_{i t}
$$

c. Model Random Effect

Model random effect menggunakan sisaan, yang dianggap memiliki hubungan antara cross section dan time series. Model random effect [6]

$$
Y_{i t}=\beta_{0}+\beta_{1} X_{1 i t}+\beta_{2} X_{2 i t}+\beta_{3} X_{3 i t}+\cdots+\beta_{j} X_{j i t}+\varepsilon_{i t}
$$

dimana $\varepsilon_{i t}$ terdiri dari $u_{i}$ dan $e_{i t}$.

\subsection{Uji Chow}

Uji Chow digunakan untuk memilih antara model fixed effect dengan model common effect, dengan hipotesis [3]. $H_{0}$ akan ditolak jika $F_{\text {hitung }}>F_{(N-1, N T-N-K)}$ atau $p<\alpha$, sehingga model yang terpilih adalah fixed effect. Statistik uji chow sebagai berikut

$$
F_{\text {hitung }}=\frac{\left(R S S_{1}-R S S_{2}\right) /(N-1)}{R S S_{2} /(N T-N-K)}
$$

$R S S_{1}$ adalah residual sum of squares teknik CEM, $R S S_{2}$ adalah residual sum of squares teknik FEM, $N$ adalah cross section, $K$ adalah banyak variabel independen, dan $T$ adalah jumlah periode waktu.

\subsection{Uji Hausman}

Memilih model random effect atau model fixed effect yang baik digunakan untuk regresi data panel, dengan hipotesis [2]. $H_{0}$ akan ditolak jika $H>\chi^{2}(K)$ atau $p<\alpha$, sehingga model yang terpilih adalah fixed effect. Statistik uji Hausman adalah

$$
H=\left[\widehat{\boldsymbol{\beta}}_{R E}-\widehat{\boldsymbol{\beta}}_{F E}\right]^{\prime}\left[\boldsymbol{\Sigma}_{R E}-\boldsymbol{\Sigma}_{F E}\right]^{-1}\left[\widehat{\boldsymbol{\beta}}_{R E}-\widehat{\boldsymbol{\beta}}_{F E}\right]
$$

$\widehat{\boldsymbol{\beta}}_{\boldsymbol{R} E}$ adalah penduga parameter model random effect, $\widehat{\boldsymbol{\beta}}_{\boldsymbol{F E}}$ adalah penduga parameter model fixed effect, $\boldsymbol{\Sigma}_{\boldsymbol{R} \boldsymbol{E}}$ adalah matriks kovariansi model random effect, dan $\boldsymbol{\Sigma}_{\boldsymbol{F E}}$ adalah matriks kovariansi model fixed effect.

\section{Metode Analisis}

\subsection{Sumber Data}

Data yang digunakan adalah data sekunder TPT kabupaten/kota di Pulau Jawa beserta faktor-faktor yang mempengaruhi periode waktu 2010 sampai 2016 yang diperoleh dari BPS. Unit penelitian ini adalah 119 kabupaten/kota yang tersebar di Pulau Jawa. 


\section{Hasih Pratiwi, Ardina Nilam Prawastyorini, Sugiyanto}

\subsection{Identifikasi Variabel}

Variabel yang digunakan pada penelitian ini adalah

1. Angkatan kerja (ribu orang).

2. Angka partisipasi kasar SMA (\%).

3. Rasio ketergantungan (\%).

4. Produk domestik regional bruto (juta rupiah).

5. Upah minimum kabupaten/kota (rupiah).

6. Jumlah penduduk (ribu orang).

7. Inflasi (\%).

8. Indeks pembangunan manusia (\%).

\subsection{Metode Analisis}

Langkah-langkah yang dilakukan terkait dengan penelitian ini sebagai berikut.

1. Pengumpulan data sekunder.

2. Mengestimasi parameter model common effect menggunakan metode kuadrat terkecil.

3. Mengestimasi parameter model fixed effect menggunakan metode least square dummy variable.

4. Mengestimasi parameter model random effect menggunakan metode generalized least square.

5. Memilih model terbaik antara common effect dan fixed effect menggunkan uji Chow apabila $H_{0}$ ditolak dilanjutkan pada uji Hausman.

6. Memilih model terbaik antara fixed effect dan random effect menggunkan uji Hausman apabila $H_{0}$ ditolak maka model fixed effect terpilih sebagai model terbaik.

7. Melakukan uji signifikansi parameter menggunakan uji simultan dan uji parsial.

8. Menarik kesimpulan.

\section{Hasil dan Pembahasan}

Pada penelitian ini menggunakan variabel dependen tingkat pengangguran terbuka $(Y)$, sedangkan variabel independen yang digunakan dalam penelitian ini adalah angkatan kerja $\left(X_{1}\right)$, angka partisipasi kasar $\left(X_{2}\right)$, rasio ketergantungan $\left(X_{3}\right)$, produk domestik regional bruto $\left(X_{4}\right)$, upah minimum kabupaten/kota $\left(X_{5}\right)$, jumlah penduduk $\left(X_{6}\right)$, inflasi $\left(X_{7}\right)$, dan indeks pembangunan manusia $\left(X_{8}\right)$. Model common effect, fixed effect, dan random effect diterapkan untuk memodelkan TPT kabupaten/kota di Pulau Jawa. Model terbaik akan dipilih untuk memodelkan TPT kabupaten/kota di Pulau Jawa. Ketiga model tersebut dipilih menggunakan uji Chow dan uji Hausman. Hasil uji Chow diperolah nilai $F_{\text {hitung }}=30,376>F_{(118 ; 706)}=1,188$ dan $p=0,000<\alpha=0,05$ maka $H_{0}$ ditolak yang berarti model fixed effect dipilih untuk mengestimasi parameter model. Selanjutnya karena model fixed effect terpilih sebagai model terbaik dilanjutkan ke uji Hausman. Berdasarkan hasil uji Hausman diperoleh nilai $H=$ $60,298>\chi^{2}(8)=15,51 p=0,000<\alpha=0,05$ maka $H_{0}$ ditolak yang berarti model fixed effect dipilih untuk mengestimasi parameter model. Hal tersebut disimpulkan bahwa model terbaik untuk memodelkan TPT kabupaten/kota di Pulau Jawa adalah model fixed effect.

Pengujian parameter untuk model fixed effect melalui uji simultan dan uji parsial. Berdasarkan pengujian simultan didapatkan nilai $F_{\text {hitung }}=26,139>F_{0,05 ; 8 ; 817}=1,678$ dan 


\section{Hasih Pratiwi, Ardina Nilam Prawastyorini, Sugiyanto}

$p=0,000<\alpha=0,05$, maka dapat diputuskan $H_{0}$ ditolak. Sedangkan uji parsial untuk masingmasing variabel sebagai berikut.

Tabel 1. Hasil Uji Parsial Fixed Effect Semua Variabel

\begin{tabular}{cccc}
\hline Variabel & Koefisien & $t_{\text {hitung }}$ & $p$ \\
\hline Konstan & 5,171 & 4,316 & 0,000 \\
$X_{1}$ & $-6,47 \times 10^{-7}$ & $-4,717$ & 0,000 \\
$X_{2}$ & 0,0007 & 0,162 & 0,871 \\
$X_{3}$ & $-2.72 \times 10^{-8}$ & $-3,869$ & 0,000 \\
$X_{4}$ & $-7,45 \times 10^{-8}$ & $-0,094$ & 0,925 \\
$X_{5}$ & $-0,016$ & $-0,886$ & 0,376 \\
$X_{6}$ & 0,021 & 1,248 & 0,213 \\
$X_{7}$ & $-1,82 \times 10^{-10}$ & $-0,010$ & 0,992 \\
$X_{8}$ & 0,039 & 2,654 & 0,008 \\
\hline
\end{tabular}

Tabel 1. Menunjukkan pengujian secara parsial, nilai $H_{0}$ akan ditolak jika nilai $\left|t_{\text {hitung }}\right|$ masingmasing variabel $>t_{(0,025 ; 700)}=1,96$ dan nilai $p<\alpha=0,05$. Berdasarkan Tabel 1 . Variabel yang berpengaruh signifikan terhadap TPT kabupaten/kota di Pulau Jawa adalah $X_{1}, X_{3}$, dan $X_{8}$. Selanjutnya, ketiga variabel tersebut diuji signifikansi parameter. Berdasarkan pengujian simultan didapatkan nilai $F_{\text {hitung }}=27,283>F_{0,05 ; 3 ; 829}=2,090$ dan $p=0,000<\alpha=0,05$, maka dapat diputuskan $H_{0}$ ditolak. Sedangkan uji parsial untuk masing-masing variabel sebagai berikut.

Tabel 2. Hasil Uji Parsial Ketiga Variabel

\begin{tabular}{cccc}
\hline Variabel & Koefisien & $t_{\text {hitung }}$ & $p$ \\
\hline Konstan & 6,170 & 9,538 & 0,000 \\
$X_{1}$ & $-5,74 \times 10^{-7}$ & $-4,5161$ & 0,000 \\
$X_{3}$ & $-2,76 \times 10^{-8}$ & $-4,068$ & 0,000 \\
$X_{8}$ & 0,044 & 3,149 & 0,002 \\
\hline
\end{tabular}

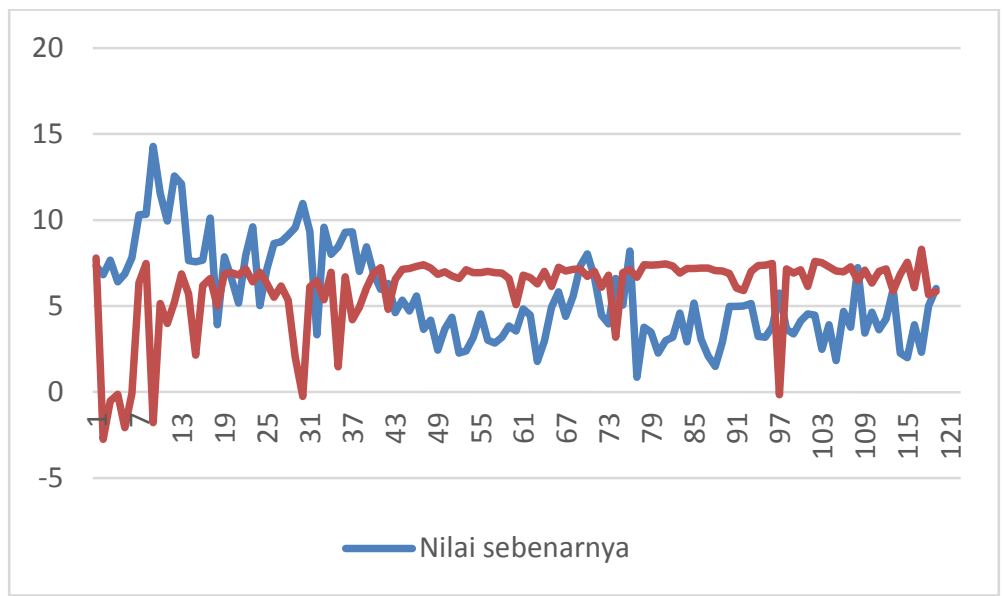




\section{Hasih Pratiwi, Ardina Nilam Prawastyorini, Sugiyanto}

Gambar 1. Perbandingan Nilai TPT Sebenarnya dan Hasil Estimasi.

Tabel 2. Merupakan pengujian parsial dengan nilai $\left|t_{\text {hitung }}\right|$ masing-masing variabel $>$ $t_{(0,025 ; 711)}=1,96$ dan nilai $p<\alpha=0,05$, maka dapat diputuskan $H_{0}$ ditolak, maka variabel $X_{1}, X_{3}$, dan $X_{8}$ berpengaruh signifikan terhadap TPT kabupaten/kota di Pulau jawa.

Estimasi parameter model fixed effect untuk memodelkan TPT kabupaten/kota di Pulau jawa sebagai berikut

$$
\hat{Y}_{i t}=6,170-5,74 \times 10^{-7} X_{1 i t}-2,76 \times 10^{-8} X_{3 i t}+0,044 X_{8 i t}
$$

Hasil estimasi model fixed effect mempunyai nilai adjusted $-R^{2}$ sebesar 79,26 persen. Nilai adjusted $-R^{2}$ sebesar 79,26 persen dapat diartikan bahwa variabel independen pada model fixed effect dapat menjelaskan variabilitas TPT kabupaten/kota di Jawa Timur sebesar 79,26 persen sedangkan 20,74 persen dijelaskan variabel lain yang belum masuk ke dalam model. Perbandingan nilai TPT sebenarnya dengan hasil estimasi tidak terlalu jauh diperoleh nilai TPT sebenarnya di Pulau Jawa sebesar 5,58\% dan nilai TPT hasil estimasi sebesar 6,01, sehingga model fixed effect baik untuk memodelkan TPT kabupaten/kota di Pulau Jawa. Gambar 1 menunjukkan perbandingan nilai TPT sebenarnya dan hasil estimasi, sedangkan Gambar 2 menunjukkan nilai TPT masing-masing kabupaten/kota.
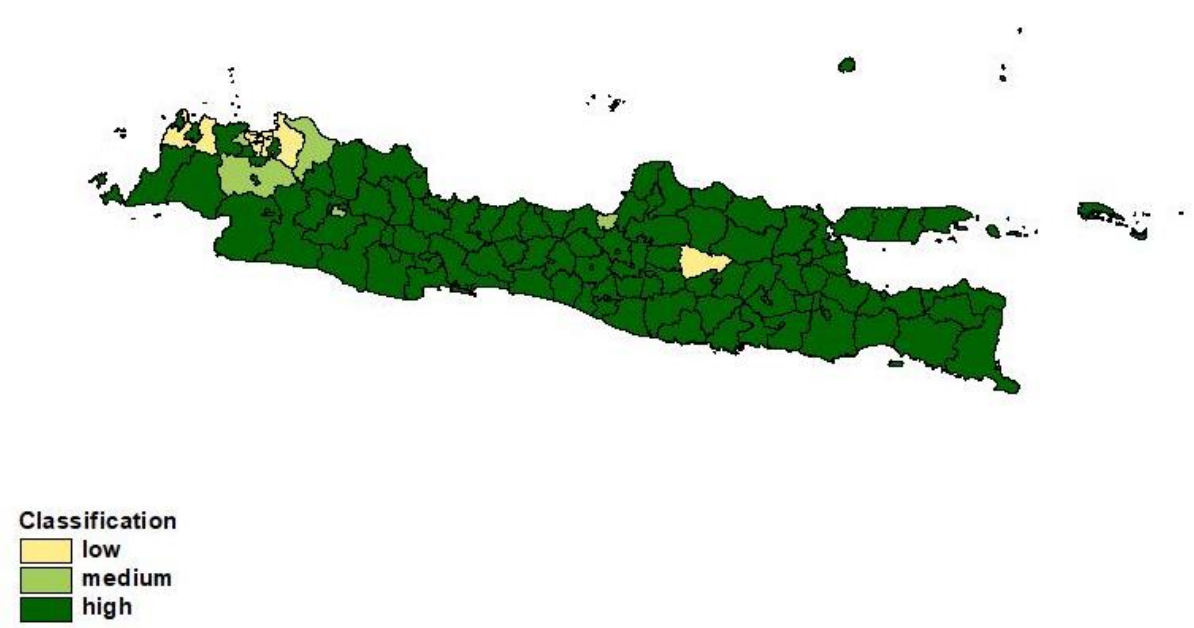

Gambar 2. Klasifikasi nilai TPT

Berdasarkan Gambar 2 daerah dengan TPT rendah $(X<0,94 \%)$ digambarkan dengan warna krem. Daerah dengan TPT sedang $(0,94 \% \leq X<4,62 \%)$ digambarkan dengan warna hijau muda, sedangkan daerah dengan TPT tinggi $(X \geq 4,62 \%)$ digambarkan dengan warna hijau tua.

\section{Kesimpulan}




\section{Hasih Pratiwi, Ardina Nilam Prawastyorini, Sugiyanto}

Berdasarkan hasil analisis dan pembahasan pada penelitian ini dapat diperoleh kesimpulan bahwa model terbaik TPT kabupaten/kota di Pulau Jawa pada periode waktu 2010 sampai 2016 adalah model fixed effect. berdasarkan model fixed effect terdapat tiga variabel yang signifikan terhadap TPT kabupaten/kota di Pulau Jawa yaitu $X_{1}, X_{3}$, dan $X_{8}$ dengan menghasilkan nilai adjusted $R^{2}$ sebesar $79,26 \%$.

\section{Daftar Pustaka}

[1] Tingkat Pengangguran Terbuka (TPT) Menurut Provinsi, 1986-2018. https://www.bps.go.id/statictable/2014/09/15/981/tingkat-pengangguran-terbuka-tpt-menurut-provinsi-1986---2018.html.

[2] Baltagi, B.H., 2008. Econometrics Analysis of Panel Data, Fourth Edition. Chicester England: John Wiley and Sons Ltd.

[3] Greene, W. H. 2000. Econometric Analysis, Fourth Edition. New Jersey: Prentice Hall International.

[4] Gujarati, D. N., 2004. Basic Econometrics, Fourth Edition. New York: The McGraw-Hill Companies.

[5] Gujarati, D.N. dan Porter, D.C., 2009. Basic Econometrics, Fifth Edition. New York: The McGraw-Hill Companies.

[6] Hsiao, C., dan Pesaran, M. H., 2004. Random Coefficient Panel Data Models. IZA Discussion Paper, No. 1236.

[7] Nachrowi, D. N. dan Usman, H,. 2006. Pendekatan Populer dan Praktis Ekonometrika untuk Analisis Ekonomi dan Keuangan. Jakarta: Lembaga Penerbit FE UI.

[8] Nwakuya, M. T. dan Ijomah, M.A., 2017. Fixed Effect Versus Random Effects Modeling In a Panel Data Analysis: a Consideration of Economic and Political Indicators in Six African Countries. International Journal of Statistics and Applications, 275-297.

[9] Sukirno, S., 2005. Pengantar Teori Ekonomi Makro. Jakarta: PT. Raja Grafindo Persada. 